Published in final edited form as:

J Am Geriatr Soc. 2016 November ; 64(11): 2317-2321. doi:10.1111/jgs. 14465.

\title{
Predictors of Place of Death Among Patients in a Home-Based Primary and Palliative Care Program
}

\author{
Phoebe Prioleau, MPhil, MPH ${ }^{1}$, Tacara N. Soones, MD, MPH${ }^{2}$, Katherine Ornstein, PhD, \\ $\mathbf{M P H}^{2,4}$, Meng Zhang, $\mathbf{M D}^{2}$, Cardinale B. Smith, MD, MCSR ${ }^{3}$, and Ania Wajnberg, $\mathbf{M D}^{4}$ \\ ${ }^{1}$ Icahn School of Medicine at Mount Sinai, New York, New York \\ ${ }^{2}$ Department of Geriatrics and Palliative Medicine, Icahn School of Medicine at Mount Sinai, New \\ York, New York \\ ${ }^{3}$ The Samuel Bronfman Department of Medicine, Division of Hematology/Medical Oncology, \\ Icahn School of Medicine at Mount Sinai, New York, New York \\ ${ }^{4}$ The Samuel Bronfman Department of Medicine, Division of General Internal Medicine, Icahn \\ School of Medicine at Mount Sinai, New York, New York
}

\begin{abstract}
Background/Objectives-Studies consistently find that although most people would prefer a home death, at least two-thirds die in an institutional setting. The objective of this study was to investigate factors associated with place of death among patients in the Mount Sinai Visiting Doctors Program (MSVD).
\end{abstract}

Design-A retrospective chart review was performed of all MSVD patients who died in 2012 to assess predictors of place of death in the last month of life. Electronic medical records were reviewed to collect information on demographics, physician visits, and end-of-life conversations.

Setting-MSVD, a home-based primary and palliative care (HBPC) program in New York.

Participants-183 MSVD patients who were discharged from the program due to death between January 2012 and December 2012 and died at home, in inpatient hospice, or in the hospital.

Results-Of 183 patients, 103 (56\%) died at home, approximately twice the national average; 28 (15\%) died in inpatient hospice and $52(28 \%)$ died in the hospital. Bivariate analyses showed that patients who were white, $\geq 90$ years, non-Medicaid, or had a recorded place of death preference were more likely to die outside of the hospital. Diagnoses and living situation were not significantly associated with place of death. Multivariate logistic regression analysis showed no

Corresponding Author: Phoebe Prioleau, MS3, Icahn School of Medicine at Mount Sinai, 130 East $94^{\text {th }}$ Street Apt. 7C, New York, NY 10128, phoebe.prioleau@icahn.mssm.edu, Telephone: (650) 380-4983, Fax: (212) 426-5108. Alternate Corresponding Author: Ania Wajnberg, MD, The Visiting Doctors Program, 107 East $102^{\text {nd }}$ Street, 6W, New York, NY 10029 , ania.wajnberg@mountsinai.org, Telephone: (212) 241-4141, Fax: (212) 426-5108.

Author Contributions: Prioleau: data acquisition, preparation of manuscript, analysis and interpretation, study concept and design. Soones: preparation of manuscript. Ornstein: study concept and design, data analysis. Zhang: preparation of manuscript. Smith: preparation of manuscript. Wajnberg: study concept and design, preparation of manuscript.

Sponsor's Role: No sponsors. 
statistical association between place of death and home visits in the last month of life (OR: 1.21; 95\% CI: 0.52, 2.77).

Conclusion-HBPC results in a high likelihood of non-hospital death; however, certain demographic characteristics are strong predictors of death at the hospital. Among MSVD patients, home visits in the last month of life were not associated with death outside the hospital.

\section{Keywords}

End-of-life care; Place of death; Home-based primary and palliative care

\section{INTRODUCTION}

There is a widespread preference within the United States for death at home among both patients and their family members. ${ }^{1,2}$ In spite of this, only $24 \%$ of those over 65 died at home in 2007, and there was a similarly low concordance between preferred and actual place of death. ${ }^{3,4}$ One predictor of place of death is visiting an emergency department (ED) in the last month of life. ${ }^{5}$ A nationally representative study found that $77 \%$ of adults over 65 who visited the ED in their last month were admitted to the hospital and $68 \%$ of those died there. ${ }^{5}$ Other studies have found that factors such as higher socioeconomic status and endof-life conversations with health care providers are correlated with death outside the hospital. ${ }^{6}$

Home-based primary and palliative care (HBPC), by decreasing unnecessary ED visits and nursing home placement, may allow more patients to die outside of the hospital. ${ }^{78} \mathrm{HBPC}$ programs have shown a $10 \%$ decrease in ED visits and hospitalizations and a $27 \%$ decrease in skilled nursing facility days. ${ }^{7}$ Not only have HBPC programs been shown to improve patient outcomes, but they have also been shown to decrease healthcare costs. ${ }^{7,} 9-11$ However, the full impact of home-based primary care on place of death is unknown.

In order to fill this knowledge gap, this study looked in depth at the 30 days prior to death to assess the level of utilization of home-based primary and palliative care at the end of life and its association with place of death. We hypothesized that while HBPC patients would have an overall greater likelihood of dying outside the hospital than the general elderly population, patient preference, demographics, and frequency of HBPC visits would be associated with place of death. Finally, we hypothesized that patients who had more visits in the last month of life would have a greater likelihood of dying outside the hospital because of increased opportunities to communicate end-of-life preferences and manage symptoms in the home setting.

\section{METHODS}

\section{Study Design, Setting, and Participants}

This was a retrospective chart review of patients enrolled in the Mount Sinai Visiting Doctors Program (MSVD) who died in 2012. MSVD is an urban HBPC program that serves more than 1,000 adults annually residing in the Northern Manhattan area of New York, NY. The MSVD team includes 11 full-time equivalent (FTE) physicians, 6 nurse practitioners, 3 
registered nurses, 5 clinical social workers, and administrative staff. Members of the team work closely with homecare and nursing agencies, community organizations, and home hospice agencies to provide comprehensive medical care, in addition to psychosocial support and counseling to patients and caregivers (formal and informal). Clinicians conduct routine home medical visits, urgent care visits during the week and are available 24 hours a day, 7 days a week by phone. Patients are eligible for participation in the MSVD program if they meet the Medicare definition of being homebound-able to leave home only with great difficulty and for absences that are infrequent or of short duration. ${ }^{12}$ Patients were excluded from this study if their medical record omitted place of death.

\section{Measures}

The primary outcome of the study was place of death, dichotomized as death in the hospital or death outside the hospital. Death outside the hospital included patients who both died at home or in inpatient hospice. The very few patients transferred to nursing home (NH) were excluded as were unable to track their place of death (hospital vs. $\mathrm{NH}$ ).

We also collected programmatic, clinical and socio-demographic factors relevant to place of death via chart review. Programmatic factors included the presence of social work or skilled nursing involvement, length of time in the program, and the intensity of HBPC services at the end of life. Participants were said to have social work involvement if there was a documented encounter with a social worker in the last 30 days of life. Length of time in the program was dichotomized as less than or greater than one year. We defined the intensity of HBPC services at the end of life as the number of home visits occurring during the 30 days prior to death. Only visits that were made by a physician or a nurse practitioner regarding a medical concern were included. We defined patients as "high-frequency HBPC visits" if their number of visits was in the top quartile.

The following clinical factors were extracted from the medical chart: documented prior advance care planning, presence of medical comorbidities, symptom burden, and functional impairment. Prior advance care planning included the presence of a health care proxy, a documented wish not to receive CPR (DNR status) or be hospitalized, preference for place of death, or enrollment in outpatient hospice at the time of death. Medical comorbidities and functional status were all recorded by the primary care provider at the time of enrollment in the MSVD program. We used the Charlson Comorbidity Index to quantify medical comorbidities. The Charlson Comorbidity Index contains 19 comorbid diagnoses and has been shown to predict 10 -year mortality. A higher score correlates with a worse prognosis. ${ }^{13}$

We also reported pain, nausea, vomiting and respiratory difficulties because studies have found that these symptoms may correlate with place of death. ${ }^{14}$ Functional impairment included Lawton and Brody's Activities of Daily Living (ADLs) and Instrumental Activities of Daily Living (IADLs). ${ }^{15}$ We recorded patients' Karnofsky Performance Scale status, a scale from 0 to 100 in 10 point increments describing functional impairment, where 100 is no evidence of disease or complaints and 0 is dead. ${ }^{16}$ We dichotomized the Karnofsky as $\checkmark 50$ or $\nsucceq 0$, as this is the cut-off for being able to care for most one's self-care needs with only occasional assistance. ${ }^{16}$ 
Finally, we abstracted socio-demographic factors related to place of death. This included age at death (dichotomized as $<90$ or $\$ 90$ ), sex, race/ethnicity, and Medicaid insurance and the presence of a paid caregiver in the last 30 days of life as determined by mention in the chart.

\section{Analysis}

We used descriptive statistics to calculate the prevalence of death in the hospital and outside the hospital in an HBPC program. We also performed Chi-square tests to look at bivariate associations between place of death and programmatic, clinical and socio-demographic factors. Multivariate logistic regression analysis controlling for factors significant in bivariate analyses was performed to examine the association between frequency of HBPC visits and place of death. Outpatient hospice was strongly correlated with our outcome variable of death outside the hospital (correlation coefficient $=0.481$ ); therefore we did not include it in the model. To assess goodness-of-fit, ROC curves with the continuous risk score from the model and place of death as outcome were calculated. ${ }^{17}$ Data were analyzed with SPSS Version 22 (IBM, Armonk, NY).

\section{RESULTS}

Of the 189 deaths in the HBPC program in 2012, 183 were included in this analysis. Three percent $(n=6)$ patients were excluded because place of death was not recorded. Of the patients included in our study, $131(71 \%)$ died outside the hospital, either at home (56\%) or in inpatient hospice (15\%). 52 (28\%) died in the hospital (Table 1).

Overall, $47 \%$ of the patients were over 90 years old at the time of death, with $7 \%$ over 100 . The majority $(75 \%)$ was female. The patients were from a variety of racial/ethnic backgrounds, reflecting the diversity of the patient population in Manhattan, specifically within the Upper East Side and East Harlem communities. 49\% of the patients were white and $15 \%$ lived alone at the time of enrollment. The remainder lived with a paid caregiver, spouse, child, or others. $46 \%$ of the patients had a Charlson score of 1 or 2, while $18 \%$ of the patients had a Charlson score $25 .{ }^{13} 88 \%$ of the total number of patients in this study were DNR at the time of death, with no significant difference between those who died in the hospital or outside the hospital.

Patients were more likely to die outside the hospital if they were $\geq 90$ years old $(\mathrm{p}=0.02)$, white race/ethnicity $(\mathrm{p}<0.001)$, receiving hospice services at home $(\mathrm{p}<.001)$, or had stated a preference not to be hospitalized ( $\mathrm{p}=0.04)$. In contrast, patients with Medicaid insurance were less likely to die outside the hospital $(\mathrm{p}=0.02)$. There was no difference in the mean number of HBPC visits in the last month of life between patients who died outside or in the hospital $(\mathrm{p}=0.5)$.

Patients who received $\geq 2$ home visits in the last month of life were in the top quartile in terms of visits and were in the category "high-frequency HBPC visits." Multivariate logistic regression analysis controlling for age, race/ethnicity, Medicaid status, and documented preference for no hospitalization showed that being in the category of high-frequency HBPC visits was not significantly associated with dying outside the hospital $(\mathrm{p}=0.66$, Table 2$)$. 


\section{DISCUSSION}

This study explored the prevalence of death outside of the hospital among patients receiving home-based primary and palliative care (HBPC) and predictors for place of death. We found that the prevalence of death at home was approximately twice as high among patients enrolled in this HBPC program than the national average of $24-30 \%{ }^{1}$ suggesting that HBPC can enable patients to remain at home at the end of life.

We hypothesized that patients who had multiple visits at the end of life would be more likely to die outside the hospital, given that they would be in close touch with the HBPC team and have ample opportunities to discuss their end-of-life preferences. However, there was very little variation in the number of visits, and patients in the top quartile of visit frequency did not have an increased likelihood of having a non-hospital death than other homebound patients. In both bivariate and multivariate analyses, patients in the top quartile of visit frequency were no more likely to die in one place or the other.

There are several explanations for our findings. First, MSVD already provides high-intensity HBPC; patients enrolled in the program have regular visits, access to urgent visits within 24 hours of an acute complaint, and can reach an on-call provider by phone 24 hours per day. With this level of access, the number of in-person visits by a clinician may not influence patient outcome.

This study reveals that there are several significant determinants of place of death among patients in HBPC. Patients $\geq 90$ years were more likely to die outside the hospital than those $<90$. While other studies have shown conflicting results concerning age, these results suggest that HBPC programs such as MSVD can successfully maintain the very elderly at home.${ }^{14}$ Karnofsky score at time of admission to HBPC and presence of a caregiver were not statistically significant determinants of place of death, reinforcing the conclusion that MSVD can facilitate death outside the hospital regardless of a patient's functional status and home support. It is also noteworthy that those in HBPC with dementia were no more likely to die in the hospital than those without dementia. This is in contrast to other studies that have reported that patients with dementia are more likely to die either in the hospital or in nursing homes. ${ }^{18}$ Additionally, there was no difference between the numbers of patients with dementia who received home hospice as those without dementia ( $48.2 \%$ vs. $48.0 \%)$.

Patients with a recorded preference for death outside the hospital were more likely to die at home or in inpatient hospice than patients without this recorded preference. This sheds light on the importance of end-of-life conversations between the patient or patient's family and the primary care provider. Such "kitchen table discussions" have been advocated by other studies and shown to improve patients' understanding of their health, options, and resources. ${ }^{2}$ The fact that such a large percentage of MSVD patients were DNR at the time of death is an indication that many of these "kitchen table discussions" were likely taking place already; however, completing the DNR form may not be enough to ensure palliative death or death at home if that is the preference.

This study demonstrates that despite the equal access to care in an HBPC program, disparities in place of death remain and SES and race/ethnicity are important determinants of 
place of death. Our study shows that being non-white and having low SES are associated with dying in the hospital. These findings are widely supported in the literature. ${ }^{19}$ Authors of other studies note that there is variation in end-of-life care among different racial/ethnic groups, for reasons that are often poorly understood. ${ }^{4,}{ }^{18}$ Even with equal access to care, race and ethnicity may influence place of death in several ways including different cultural preferences around aging, illness and death, familial expectations regarding care, language and educational barriers, and varying levels of caregiver support. The results of this study suggest that additional research is needed to determine the precise role of race/ethnicity. Similarly, patients with Medicaid insurance were also less likely to die outside the hospital than those without Medicaid. This is consistent with prior research demonstrating that even among patients with access to hospice services, those of lower SES were more likely to die in the hospital. ${ }^{1}$ Our study suggests that access to care does not explain this Medicaid disparity sufficiently and further studies are required to understand the roots of these inequalities.

Previous studies have divided patients into those who die at home and those who die in an institution. These categories had drawbacks for this particular study and the categories "death in the hospital" vs. "death outside the hospital" were chosen instead. ${ }^{3}$ First, the care patterns of nursing home patients were not accessible. Second, inpatient hospice is consistent with the goals of care of a preference for home death: it prioritizes comfort and provides a home-like environment with family involvement.

Our study has several limitations worth noting. The first is that a retrospective chart review will not capture all advance care planning conversations or patient wishes. As a result, we were not able to look at concordance of place of death with patient preferences, a more important outcome of advance care planning. Second, patient preference for place of death was only captured during the last 30 days and conversations about preference that may have occurred before this time period were not captured. Therefore, the number of patients who preferred a home death might have been higher. Ideally, we would have looked at a period longer than 30 days, but the in-depth nature of this chart review meant that this was not feasible. Third, there may be a selection bias: patients who enroll in home-based primary care may be more likely to think about their end-of-life preferences than those in the general population, and thus be more likely to ultimately die in their preferred place.

Another limitation is that clinical data, such as comorbidities and functional status, were collected at the time of the patient's enrollment in MSVD and may not accurately reflect a patient's state at the end of life. The Charlson score, on the other hand, was calculated based on the most recent list of diagnoses and should be a more accurate reflection of the patient's status at the time of death. Additionally, we were unable to collect data on patients' cultural preferences for place of death which may contribute to some of our disparities among racial and ethnic minorities. However, we did capture patients personal preferences for desires of place of death. Finally, our study was limited to the MSVD population and our results may not be generalizable to other HBPC programs, particularly those in non-urban locations. ${ }^{3}$ Nonetheless, our study provides an important first step in understanding the role of HBPC in promoting greater congruence between preferred and actual place of death. 
This study highlights some of the advantages of HBPC at the end-of-life, especially with regard to planning for place of death. HBPC and similar care models may be effective in allowing patients to remain at home, if that is where they prefer to die. HBPC is associated with a higher likelihood of dying at home regardless of frequency of visits at the end of life. Disparities remain with respect to ethnicity and socioeconomic status, however; future studies will need to explore these end-of-life care differences in more depth.

\section{Acknowledgments}

Conflict of Interest: The authors have no financial or any other kind of personal conflicts with this paper.

\section{References}

1. Barclay JS, Kuchibhatla M, Tulsky JA, et al. Association of hospice patients' income and care level with place of death. JAMA Intern Med. 2013; 173:450-456. [PubMed: 23420383]

2. Ratner E, Norlander L, McSteen K. Death at home following a targeted advance-care planning process at home: the kitchen table discussion. J Am Geriatr Soc. 2001; 49:778-781. [PubMed: 11454117]

3. Burge F, Lawson B, Johnston G, et al. Primary care continuity and location of death for those with cancer. J Palliat Med. 2003; 6:911-918. [PubMed: 14733683]

4. Fischer S, Min SJ, Cervantes L, et al. Where do you want to spend your last days of life? Low concordance between preferred and actual site of death among hospitalized adults. J Hosp Med. 2013; 8:178-183. [PubMed: 23440934]

5. Smith AK, McCarthy E, Weber E, et al. Half of older Americans seen in emergency department in last month of life; most admitted to hospital, and many die there. Health Aff (Millwood). 2012; 31:1277-1285. [PubMed: 22665840]

6. Fromme EK, Bascom PB, Smith MD, et al. Survival, mortality, and location of death for patients seen by a hospital-based palliative care team. J Palliat Med. 2006; 9:903-911. [PubMed: 16910805]

7. De Jonge KE, Jamshed N, Gilden D, et al. Effects of home-based primary care on Medicare costs in high-risk elders. J Am Geriatr Soc. 2014; 62:1825-1831. [PubMed: 25039690]

8. Kronhaus A. Home-based primary care: an innovative practice model for reducing costs and improving quality of care. N C Med J. 2014; 75:332-333. [PubMed: 25237873]

9. Wajnberg A, Wang KH, Aniff M, et al. Hospitalizations and skilled nursing facility admissions before and after the implementation of a home-based primary care program. J Am Geriatr Soc. 2010; 58:1144-1147. [PubMed: 20487075]

10. Edes T, Kinosian B, Vuckovic NH, et al. Better access, quality, and cost for clinically complex veterans with home-based primary care. J Am Geriatr Soc. 2014; 62:1954-1961. [PubMed: 25333529]

11. Stall N, Nowaczynski M, Sinha SK. Systematic review of outcomes from home-based primary care programs for homebound older adults. J Am Geriatr Soc. 2014; 62:2243-2251. [PubMed: 25371236]

12. [Accessed October 1, 2015] Home health—clarification to benefit policy manual language on "confined to the home" definition. Department of Health and Human Services (online). Available at: www.cms.gov/Outreach-and-Education/Medicare-Learning-Network-MLN/ MLNMattersArticles/downloads/MM8444.pdf

13. Charlson ME, Pompei P, Ales KL, et al. A new method of classifying prognostic comorbidity in longitudinal studies: development and validation. J Chronic Dis. 1987; 40:373-383. [PubMed: 3558716]

14. Grande GE, Addington-Hall JM, Todd CJ. Place of death and access to home care services: are certain patient groups at a disadvantage? Soc Sci Med. 1998; 47:565-579. [PubMed: 9690840]

15. Lawton MP, Brody EM. Assessment of older people: self-maintaining and instrumental activities of daily living. Gerontologist. 1969; 9:179-186. [PubMed: 5349366] 
16. Karnofsky, DA., JHB. The clinical evaluation of chemotherapeutic agents in cancer. In: CMM, editor. Symposium on the evaluation of chemotherapeutic agents. New York: Columbia University Press; 1949. p. 191-205.

17. Hanley JA, McNeil BJ. The meaning and use of the area under a receiver operating characteristic (ROC) curve. Radiology. 1982; 143:29-36. [PubMed: 7063747]

18. Mitchell SL, Teno JM, Intrator O, et al. Decisions to forgo hospitalization in advanced dementia: a nationwide study. J Am Geriatr Soc. 2007; 55:432-438. [PubMed: 17341248]

19. Grande GE, McKerral A, Todd CJ. Which cancer patients are referred to Hospital at Home for palliative care? Palliat Med. 2002; 16:115-123. [PubMed: 11969142]

\section{Conflict of Interest Disclosures}

\begin{tabular}{|c|c|c|c|c|c|c|c|c|}
\hline \multirow[t]{2}{*}{ Elements of Financial/Personal Conflicts } & \multicolumn{2}{|c|}{$\begin{array}{c}* \text { Author } 1 \\
\text { PP }\end{array}$} & \multicolumn{2}{|c|}{$\begin{array}{c}\text { Author } 2 \\
\text { TS }\end{array}$} & \multicolumn{2}{|c|}{$\begin{array}{c}\text { Author } 3 \\
\text { KO }\end{array}$} & \multicolumn{2}{|c|}{$\begin{array}{c}\text { Author } 4 \\
\text { MZ }\end{array}$} \\
\hline & Yes & No & Yes & No & Yes & No & Yes & No \\
\hline Employment or Affiliation & & $\mathrm{X}$ & & $\mathrm{X}$ & & $\mathrm{X}$ & & $\mathrm{X}$ \\
\hline Grants/Funds & & $\mathrm{X}$ & & $\mathrm{X}$ & & $\mathrm{X}$ & & $\mathrm{X}$ \\
\hline Honoraria & & $\mathrm{X}$ & & $\mathrm{X}$ & & $\mathrm{X}$ & & $\mathrm{X}$ \\
\hline Speaker Forum & & $\mathrm{X}$ & & $\mathrm{X}$ & & $\mathrm{X}$ & & $\mathrm{X}$ \\
\hline Consultant & & $\mathrm{X}$ & & $\mathrm{X}$ & & $\mathrm{X}$ & & $\mathrm{X}$ \\
\hline Stocks & & $\mathrm{X}$ & & $\mathrm{X}$ & & $\mathrm{X}$ & & $\mathrm{X}$ \\
\hline Royalties & & $\mathrm{X}$ & & $\mathrm{X}$ & & $\mathrm{X}$ & & $\mathrm{X}$ \\
\hline Expert Testimony & & $\mathrm{X}$ & & $\mathrm{X}$ & & $\mathrm{X}$ & & $\mathrm{X}$ \\
\hline Board Member & & $\mathrm{X}$ & & $\mathrm{X}$ & & $\mathrm{X}$ & & $\mathrm{X}$ \\
\hline Patents & & $\mathrm{X}$ & & $\mathrm{X}$ & & $\mathrm{X}$ & & $\mathrm{X}$ \\
\hline Personal Relationship & & $\mathrm{X}$ & & $\mathrm{X}$ & & $\mathrm{X}$ & & $\mathrm{X}$ \\
\hline
\end{tabular}

\begin{tabular}{|l|l|l|l|l|l|l|l|l|}
\hline Elements of Financial/Personal Conflicts & \multicolumn{2}{|c|}{$\begin{array}{c}\text { Author 5 } \\
\text { CS }\end{array}$} & \multicolumn{2}{|c|}{$\begin{array}{c}\text { Author 6 } \\
\text { AW }\end{array}$} & \multicolumn{2}{l|}{} & \multicolumn{2}{l|}{} \\
\hline & Yes & No & Yes & No & Yes & No & Yes & No \\
\hline Employment or Affiliation & & X & & X & & & & \\
\hline Grants/Funds & & $X$ & & $X$ & & & & \\
\hline Honoraria & & $X$ & & $X$ & & & & \\
\hline Speaker Forum & & $X$ & & $X$ & & & & \\
\hline Consultant & & $X$ & & $X$ & & & & \\
\hline Stocks & & $X$ & & $X$ & & & & \\
\hline Royalties & & $X$ & & $X$ & & & & \\
\hline Expert Testimony & & $X$ & & $X$ & & & & \\
\hline Board Member & & $X$ & & $X$ & & & & \\
\hline Patents & & $X$ & & $X$ & & & & \\
\hline Personal Relationship & & $X$ & & $X$ & & & & \\
\hline
\end{tabular}




\section{Table 1}

Characteristics of Study Sample by Location of Death

\begin{tabular}{|c|c|c|c|c|}
\hline Variables & All $(n=183)$ & $\begin{array}{c}\text { Death outside the hospital } \\
(\mathrm{n}=\mathbf{1 3 1})\end{array}$ & $\begin{array}{l}\text { Death inside the hospital } \\
(\mathrm{n}=52)\end{array}$ & p value \\
\hline \multicolumn{5}{|l|}{ Sociodemographics, n (\%) } \\
\hline Age $\searrow 0$ & 86 & $70(81)$ & $16(19)$ & 0.02 \\
\hline Male & 46 & $36(78)$ & $10(22)$ & 0.3 \\
\hline White race/ethnicity & 90 & $75(83)$ & $15(17)$ & $<0.001$ \\
\hline Medicaid Insurance & 102 & $66(65)$ & $36(35)$ & 0.02 \\
\hline Paid Caregiver & 157 & $114(73)$ & $43(27)$ & 0.3 \\
\hline Lives Alone & 27 & $19(70)$ & $8(30)$ & 0.9 \\
\hline \multicolumn{5}{|l|}{ Functional Status, $\mathrm{n}(\%)$} \\
\hline Karnofsky score $\mathbf{5 0}$ & 142 & $101(71)$ & $41(29)$ & 0.5 \\
\hline Dependent in $\geq 3$ ADLs & 117 & $83(71)$ & $34(29)$ & 0.9 \\
\hline \multicolumn{5}{|l|}{ Advance Care Planning, $\mathrm{n}(\%)$} \\
\hline Do Not Resuscitate (DNR request) & 161 & $118(73)$ & $43(27)$ & 0.2 \\
\hline Hospice (outpatient) & 88 & $83(94)$ & $5(6)$ & $<0.001$ \\
\hline Stated Preference for No Hospitalization & 48 & $40(83)$ & $8(17)$ & 0.04 \\
\hline \multicolumn{5}{|l|}{ Programmatic Factors, $\mathrm{n}(\%)$} \\
\hline Clinician visit in last 30 days & 126 & $89(71)$ & $37(29)$ & 0.7 \\
\hline$<1$ year in the HBPC program & 59 & $42(71)$ & $17(29)$ & 0.9 \\
\hline High frequency HBPC visits, $\mathrm{n}(\%)$ & 49 & $37(76)$ & $12(24)$ & 0.5 \\
\hline
\end{tabular}


Table 2

Multivariate Logistic Regression Analysis of Frequency of HBPC Visits and Death in the Hospital

\begin{tabular}{lll}
\hline & OR $(\mathbf{9 5 \%} \mathbf{C I})$ & p value \\
\hline Variables & & \\
High-Frequency HBPC Visits & $1.21(0.52,2.77)$ & 0.66 \\
White, non-Hispanic & $0.50(0.22,1.17)$ & 0.11 \\
Medicaid & $1.52(0.68,3.38)$ & 0.31 \\
Stated preference for no hospitalization & $0.42(0.17,1.03)$ & 0.06 \\
Age $\searrow 0$ years & $0.46(0.22,0.99)$ & 0.05 \\
Diabetes & $1.35(0.59,3.12)$ & 0.48 \\
\hline
\end{tabular}

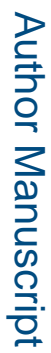

